\title{
ON A PROBLEM BY K. NIKODEM
}

\author{
ATTILA GILÁNYI
}

Abstract. Concerning a problem raised by K. Nikodem, we prove the following statement. If $G$ is an Abelian group divisible by $2, H$ is a Hilbert space and $\varepsilon$ is a nonnegative real number and a function $f: G \rightarrow H$ satisfies

$$
\|f(x-y)-2 f(x)-2 f(y)\| \leqslant\|f(x+y)\|+\varepsilon \quad(x, y \in G),
$$

then there exists a function $g: G \rightarrow H$ fulfilling

$$
g(x+y)+g(x-y)-2 g(x)-2 g(y)=0 \quad(x, y \in G)
$$

and

$$
\|f(x)-g(x)\| \leqslant \frac{5}{2} \varepsilon \quad(x \in G) .
$$

Mathematics subject classification (2000): Primary: 39B62, 39B82.

Key words and phrases: square-norm equation, functional inequality, stability.

\section{REFERENCES}

[1] J. ACZÉL, The general solution of two functional equations by reduction to functions additive in two variables and with the aid of Hamel bases, Glasnik Mat.-Fiz. Astronom. Ser. II, 20 (1965), 65-73.

[2] J. AcZÉL, J. Dhombres, Functional Equations in Several Variables, Cambridge University Press, Cambridge, 1989.

[3] A. GILÁNYI, Eine zur Parallelogrammgleichung äquivalente Ungleichung, Aequationes Math., 62 (2001), 303-309.

[4] D. H. HYERS, On the stability of the linear functional equation, Proc. Natl. Acad. Sci. USA 27 (1941), 222-224.

[5] J. L. W. V. Jensen, Om Fundamentalligningers Oplösning ven elementäre Midler, Tidsskr. Mat. (4) 2 (1878), 149-155.

[6] S. KuREPA, On the quadratic functionals, Publ. Inst. Math. Acad. Serbe Sci. Beograd 13 (1959), 57-72.

[7] S. KuREPA, On P. Volkmann's paper, Glas. Mat. Ser. III, 22(42) (1987), 371-374.

[8] Gy. MAKSA, Remark on the talk of P. Volkmann, Proc. of the Twenty-third International Symposium on Functional Equations (Gargnano, Italy, 1985), Centre for Information Theory, Faculty of Mathematics, Oniversity of Waterloo, Waterloo, Ontario, Canada, 72-73.

[9] Gy. MAKSA, P. VolKMANN, Characterization of group homomorphisms having values in an inner product space, Publ. Math. Debrecen 56 (2000), 197-200.

[10] K. NiKodeM, 7. Problem, Report of Meeting, Aequationes Math., 61 (2001), 301.

[11] F. SKOF, On some alternative quadratic equations, Results Math. 27 (1995), 402-411.

[12] F. SKOF, On some alternative quadratic equations in inner-product spaces, Atti Sem. Mat. Fis. Univ. Modena 46 (1998), 951-962.

[13] JaCEK TABOR, Józef TABOR, Solution of the 7. Problem posed by K. Nikodem, Report of Meeting, Aequationes Math., 61 (2001), 307-309.

[14] P. Volkmann, Pour une fonction réelle $f$ l'inéquation $|f(x)+f(y)| \leqslant|f(x+y)|$ et l'équation de Cauchy sont équivalentes, Proc. of the Twenty-third International Symposium on Functional Equations (Gargnano, Italy, 1985), Centre for Information Theory, Faculty of Mathematics, University of Waterloo, Waterloo, Ontario, Canada, 43. 